\title{
Microkinetic Model for the Dry Reforming of Methane on Rh Doped Pyrochlore Catalysts Felipe Polo-Garzon ${ }^{1}$, Joseph K. Scott ${ }^{1}$ and David A. Bruce ${ }^{1 *}$ \\ ${ }^{1}$ Department of Chemical and Biomolecular Engineering, 127 Earle Hall, Clemson University, Clemson, SC 29634, USA \\ *Corresponding author. Phone: +1 864656 5425. E-mail address: dbruce@ clemson.edu
}

\begin{abstract}
Dry reforming of methane (DRM) is a promising gateway technology for energy and fuels production that utilizes methane and $\mathrm{CO}_{2}$, a common contaminant in natural gas deposits, as feed. Previous experimental work has shown that Rh-substituted lanthanum zirconate pyrochlores (LRhZ) are catalytically active and stable at the high temperatures needed for DRM. Although experimental and ab initio computational approaches have been used to study aspects of the DRM reaction mechanism on pyrochlores, this work is the first to describe a microkinetic model with variable reaction conditions and catalyst metal composition that uses parameters derived from DFT simulations for DRM over the (111) plane of an LRhZ pyrochlore catalyst. This model was used to gain insight into the favored reaction pathway for DRM and evaluate the time evolution of key intermediates (e.g., $\mathrm{CH}_{3}, \mathrm{CH}_{2}, \mathrm{CH}, \mathrm{OH}, \mathrm{O}$ ) within the reactor at different reaction conditions and catalyst metal loading. Model predictions of reactant conversion and $\mathrm{H}_{2} / \mathrm{CO}$ product ratio were compared to experimental reaction data, and predicted yields compared well with experimental results.
\end{abstract}

$\begin{array}{ll}\text { Keywords: } & \text { Dry reforming } \\ & \text { Methane } \\ \text { Syngas } \\ \text { Pyrochlore } \\ \text { Microkinetic model } \\ \text { DFT } \\ \text { Reaction mechanism }\end{array}$

\section{Introduction}

The availability of shale-gas has granted $\mathrm{CH}_{4}$-related chemistry renewed attention. One efficient pathway for converting methane into useful chemicals and fuels involves the formation of syngas, a mixture of $\mathrm{CO}$ and $\mathrm{H}_{2}$. [1] Multiple routes to produce syngas are currently available: Steam Methane Reforming (SMR), Partial Oxidation (POX), Autothermal Reforming (ATR) and the Dry Reforming of Methane (DRM). Though steam reforming and autothermal reforming are currently the most widely used methods, the dry reforming of methane $\left(\mathrm{CH}_{4}+\mathrm{CO}_{2} \rightleftharpoons 2 \mathrm{CO}+2 \mathrm{H}_{2}\right.$, $\Delta \mathrm{H}^{\circ}=+247.4 \mathrm{~kJ} / \mathrm{mol}$ ) offers several advantages. Specifically, DRM yields syngas with a 
favorable $\mathrm{H}_{2}$ to $\mathrm{CO}$ ratio, and it offers the possibility of efficiently using methane from natural deposits that are rich with $\mathrm{CO}_{2}$. Current approaches for dealing with this latter problem use energy intensive processes to separate $\mathrm{CO}_{2}$ from the desired methane product, but DRM technologies could significantly reduce these costs and enable syngas-to-liquids processes to be efficiently deployed on-site near the production well, enabling the economical production of fuels from gas fields previously ignored, such as the Natuna field in the Greater Sarawak Basin in Indonesia, the largest gas field in south Asia (approximately 46 trillion cubic feet recoverable reserves), which has not been explored due to high $\mathrm{CO}_{2}$ content $(71 \%)$. [2, 3]

Despite these advantages, dry reforming has not been widely adopted due to the absence of longterm, thermally stable catalysts for the reaction, which occurs at approximately $1000 \mathrm{~K}$. In recent years, however, $\mathrm{Rh}$-substituted lanthanum zirconate pyrochlores $\left(\mathrm{La}_{2} \mathrm{Zr}_{2-\mathrm{x}} \mathrm{Rh}_{\mathrm{x}} \mathrm{O}_{7}\right)$ have been found to be catalytically active and stable for DRM. To further develop and improve these materials research efforts have sought to understand the reaction mechanism, both computationally [4] and experimentally [5-7], but these efforts failed to yield a detailed kinetic model for the overall reaction that accounted for the effects of catalyst composition and reaction conditions. Building upon this prior work, we herein present a microkinetic model (MKM) based on DFT data [4] that quantitatively describes reaction performance for DRM over Rh-doped pyrochlores and accounts for the effects of varying Rh loading in the catalyst.

In studies of other catalyst systems [8-13], DFT data have been used to build microkinetic models (MKMs) that in-turn were used to predict reaction performance. Such tools aim to reduce trial-and-error experimental efforts focused on catalyst optimization. In general, DFT-based MKMs enable a more fundamental approach to system optimization than purely parameter-fit models, as DFT-based MKMs consider a wide network of possible reaction steps, for which activation barriers are available, and do not overlook possible branching of the reaction network due to limitations in experimental data for parameter estimation. Furthermore, calculated activation energies by DFT rely on first principles calculations and consider interaction among intermediates at an atomic level.

Medford et al. [14] used DFT data to construct a mean-field MKM for the formation of ethanol via $\mathrm{CH}_{\mathrm{x}} \mathrm{CO}$ coupling to illustrate why it is difficult to find transition-metal higher alcohol catalysts. They numerically solved the coupled differential equations with the steady state approximation and included four different adsorption sites to account for the complex stepped surface. This model suggested that there is a small window of carbon and oxygen binding energies that promotes ethanol formation over methane and methanol. Although no pure metal lies in the required region, alloying and doping of materials can be used to create materials that favor ethanol production. Syngas conversion to ethanol (and higher alcohols) was experimentally and computationally approached by Prieto et al. [15], who used a DFT-based MKM to conclude that a specific $\mathrm{Co}-\mathrm{Cu}$ alloy was favorable for the production of ethanol and higher alcohols, which was then validated experimentally. This model solved the material balance for surface species following the steady state assumption and considered diffusion steps between different 
catalyst sites. Methanol production from syngas has also been studied employing a combined DFT-MKM approach. [16] In this study, the kinetic rate equations are solved to steady-state and the results showed qualitative agreement with experiment and provided information about optimum operating conditions for the reactor containing $\mathrm{ZnO}$ catalysts.

To our knowledge, the only reported work on DFT-based microkinetic modelling of DRM was the recently published study by Wang et al. [17] that employed nickel and nickel carbide catalysts. In that work, the steady-state approximation was used to solve the reaction rate equations for 8 elementary steps and two equilibrium processes, which included the adsorption of $\mathrm{CO}$ and the dissociative adsorption of hydrogen. Though this study offers useful insight into the DRM reaction mechanism, the present work is much more comprehensive in nature and constitutes the first DFT-based MKM for DRM on pyrochlore catalysts.

In our previous DFT based computational work [4], the main reaction pathway for DRM on $\mathrm{LRhZ}$ catalysts was discerned from the activation barriers of a proposed reaction network. This qualitative approach to the main reaction pathway is taken to a further level in the present work; specifically, an MKM is developed to obtain quantitative information about DRM product yields at different reaction conditions and with catalysts of varying Rh metal loading. The predictions of the model are compared to experimental data for LRhZ catalyst activity [5] and used to explain overall catalyst activity and resistance to fouling as well as the role (active intermediate or spectator) played by different surface species.

\section{Theory}

\subsection{Density functional theory (DFT)}

The activation energies for reactions used in the present MKM were previously calculated [4] by first principles techniques using the Vienna ab initio simulation package (VASP) [18-21], which is based on a plane-wave DFT code. Previously, it was shown [22] that the lattice parameter calculations as well as the trends in surface stability and reactivity for $\mathrm{Rh}_{2} \mathrm{O}_{3}$ surfaces were very similar using DFT or DFT+U methods. Therefore, to reduce computational efforts, the calculations reported in our previous study [4] only used DFT methods and entropy corrections were not included, further explanation can be found in the Supporting Information in the section titled 'Entropy contribution'. The projector augmented wave (PAW) pseudopotentials were used $[23,24]$. The exchange-correlation functional employed was the generalized gradient approximation using the implementation of Perdew, Burke and Ernzerhof (GGA-PBE) [25]. Further details can be found in our earlier published work [4].

The complete set of elementary steps considered in the reaction network on the (111) plane of the LRhZ catalyst consists of 62 reactions, counting both forward and reverse reactions. Some activation energies were derived from rigorous DFT calculations (CI-NEB method), while others 
were estimated by a Bronsted-Evans-Polanyi (BEP) relation derived from DFT data. A detailed description of the procedure used to calculate individual activation barriers in the reaction network can be found in [4].

\subsection{Microkinetic model (MKM)}

To quantitatively describe the extent of reaction and the concentration of intermediate species on the catalyst surface, an MKM for DRM on the (111) plane of the LRhZ pyrochlore catalyst was developed. A batch reactor was modeled and all elementary reaction steps shown in Fig. 1 were considered. This reaction network, which accounts for adsorption, desorption and surface reactions, includes a total of 62 reactions. The model was implemented in the package SUNDIALS (SUite of Nonlinear and DIfferential/ ALgebraic equation Solvers), more specifically the CVODE code, that solves initial value problems for ordinary differential equation (ODE) systems [26, 27]. The relative tolerance and absolute tolerance for solved variables were set to $1 \times 10^{-20}$ and $1 \times 10^{-8}$, respectively. Additionally, the material balances for $\mathrm{C}$, $\mathrm{H}$ and $\mathrm{O}$ atoms inside the reactor allowed for a direct cross-checking of the solver results. Following the time evolution of the variables allowed us to follow the reaction progression as it approached steady-state. This helped verify the meaning of the coverages obtained, which can be an issue when solving for static variables at steady-state conditions.

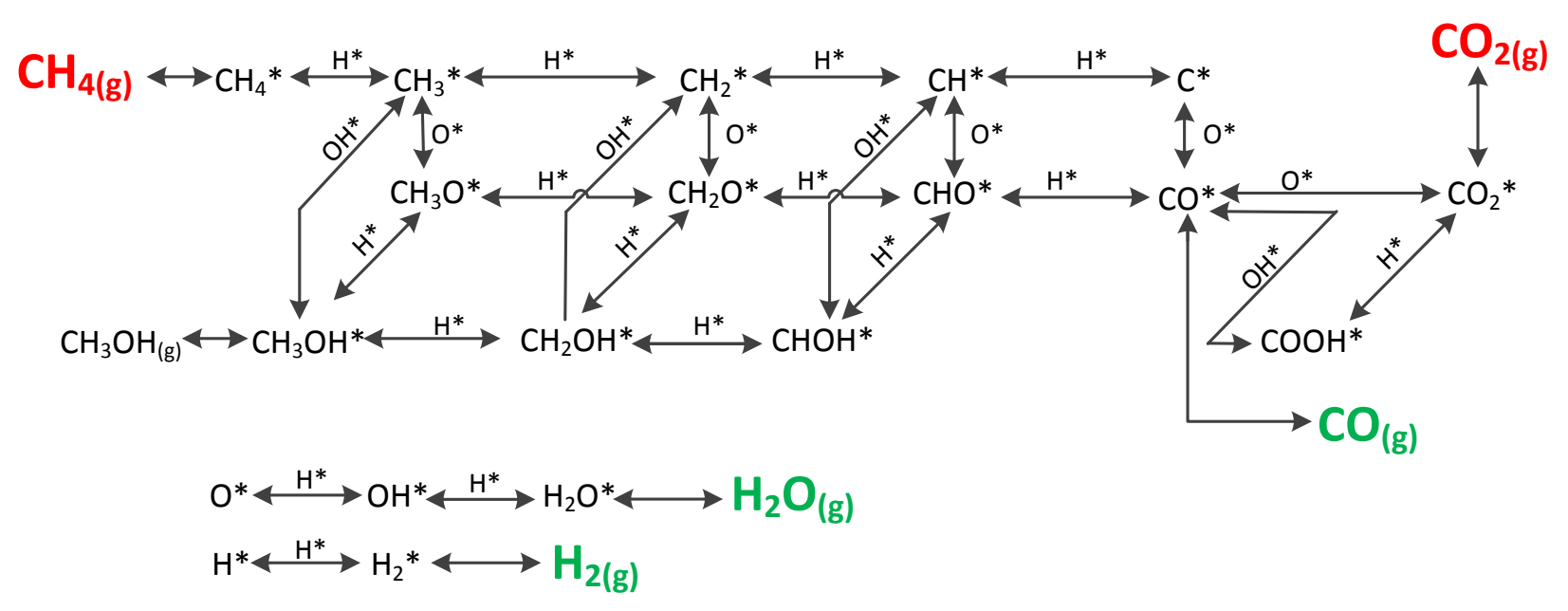

Fig. 1 DRM reaction network on the (111) plane of the LRhZ pyrochlore catalyst. Reprinted from J. Catal., 333, Felipe Polo-Garzon, Ming He, David A. Bruce, Ab Initio Derived Reaction Mechanism for the Dry Reforming of Methane on Rh Doped Pyrochlore Catalysts, 59-70, Copyright (2016), with permission from Elsevier [4].

The pyrochlore MKM for DRM consists of a set of ordinary differential equations (ODEs) corresponding to the net change of surface coverage of particular species with respect to time 
and a second set of ODEs corresponding to the change of gas phase species with respect to time, also known as the design equation of the batch reactor. It should also be noted that the equations describing adsorption rates differ from those used to describe surface reaction and desorption rates. This is because the driving force and physical nature of these processes are inherently of a different nature; namely, the partial pressure and kinetic energy of the gas phase species combined with the availability of vacant surface sites controls rates of adsorption, while surface concentrations combined with vibrational and electronic states control the rates of surface reaction and desorption processes. In the model, the initial coverage of surface species is set to zero and the diffusion of two species apart from each other is assumed to be a nearly barrierless process. Additionally, all DFT derived $\Delta \mathrm{E}_{\text {act }}$ values were scaled by 0.66 , which is the ratio between the reaction energy for DRM from enthalpies of formation and the value calculated from DFT. [4]

\section{Adsorption and desorption processes}

Collision theory may be used to estimate rate constants for adsorption processes. In the work reported by Cortright and Dumesic [28], it is shown that for these processes, the rate of adsorption is given by:

$$
r_{f, a d s}=\frac{\omega}{\sqrt{2 \pi m_{A} k_{B} T}} \exp \left[\frac{-E_{f, a d s}}{k_{B} T}\right] \sigma^{\circ}(T, \theta) P_{A(g)}
$$

where $r_{f, a d s}$ is the rate of adsorption with units of coverage (molecules/active site) per time, $m_{A}$ is the molecular weight of the adsorbing species $A, k_{B}$ is the Boltzmann constant, $E_{f, a d s}$ is the activation energy for adsorption, $\omega$ is the area per active site $\left(\omega=1.28 \times 10^{-19} \mathrm{~m}^{2}\right.$ per active site, for the (111) LRhZ plane), $P_{A(g)}$ is the partial pressure of the adsorbant $A$, and $\sigma^{\circ}(T, \theta)$ is the sticking probability of $A$ on the catalyst surface, which is a function of temperature $T$ and coverage $\theta$ and represents the probability that a collision with the surface leads to adsorption. In this work, the adsorption processes are assumed to be nearly barrierless and the energy term $E_{f}$, ads was therefore set equal to zero. Furthermore, the sticking probability can be approximated as the coverage of empty sites $\left(\theta^{* \mathrm{Rh}}\right.$ or $\theta^{*}$ depending on whether the molecule preferably adsorbs to $\mathrm{Rh}$-containing or non-Rh-containing sites, respectively); this assumption implies setting the value of the rate constant for adsorption as an upper limit. In our previous study on steady-state isotopic tracing [5], it was confirmed that $\mathrm{CO}_{2}$ adsorbs and desorbs from the surface; thus, the present model considers the reversible adsorption of reactants. The rate of adsorption for the reactants is expressed as,

$$
\begin{aligned}
& \mathrm{r}_{1, \mathrm{f}}=\mathrm{k}_{1, \mathrm{f}} \theta^{* \mathrm{Rh}} \mathrm{P}_{\mathrm{CH}_{4}(\mathrm{~g})}, \mathrm{k}_{1, \mathrm{f}}=\frac{\omega}{\sqrt{2 \pi \mathrm{m}_{\mathrm{CH}_{4}} \mathrm{k}_{\mathrm{B}} \mathrm{T}}} \\
& \mathrm{r}_{6, \mathrm{f}}=\mathrm{k}_{6, \mathrm{f}} \theta^{*} \mathrm{P}_{\mathrm{CO}_{2}(\mathrm{~g})}, \mathrm{k}_{6, \mathrm{f}}=\frac{\omega}{\sqrt{2 \pi \mathrm{m}_{\mathrm{CO}_{2}} \mathrm{k}_{\mathrm{B}} \mathrm{T}}}
\end{aligned}
$$


and desorption rates are assumed to be first order processes with rate constants calculated using an Arrhenius Law expression:

$$
\begin{aligned}
& \mathrm{r}_{1, \mathrm{r}}=\mathrm{k}_{1, \mathrm{r}} \theta_{\mathrm{CH}_{4}}, \mathrm{k}_{1, \mathrm{r}}=\operatorname{Aexp}\left[\frac{-\mathrm{E}_{\mathrm{des}, \mathrm{CH}_{4}}}{\mathrm{k}_{\mathrm{B}} \mathrm{T}}\right] \\
& \mathrm{r}_{6, \mathrm{r}}=\mathrm{k}_{6, \mathrm{r}} \theta_{\mathrm{CO}_{2}}, \mathrm{k}_{6, \mathrm{r}}=\operatorname{Aexp}\left[\frac{-\mathrm{E}_{\mathrm{des}, \mathrm{CO}_{2}}}{\mathrm{k}_{\mathrm{B}} \mathrm{T}}\right]
\end{aligned}
$$

R1 and R6 are steps corresponding to the reversible adsorption of the two reactants $\mathrm{CH}_{4}$ and $\mathrm{CO}_{2}$, respectively (see Supporting Information, Table S3). In a similar manner, the reversible desorption of products was also considered. And so, the equilibrium constants for adsorption are defined as $\mathrm{K}_{1, \mathrm{eq}}=\mathrm{k}_{1, \mathrm{f}} / \mathrm{k}_{1, \mathrm{r}}$ for $\mathrm{CH}_{4(\mathrm{~g})}$ adsorption and $\mathrm{K}_{6, \mathrm{eq}}=\mathrm{k}_{6, \mathrm{f}} / \mathrm{k}_{6, \mathrm{r}}$ for $\mathrm{CO}_{2(\mathrm{~g})}$ adsorption. Analogous definitions of the equilibrium constant were used for the reversible desorption of products.

\section{Surface reactions}

In our previous DFT based computational work [4], the activation energies were calculated for each of the elementary reaction steps shown in Fig. 1. In both works, it was chosen to combine the energetics associated with the diffusion of reactants to neighboring surface sites and reaction processes involving those species into a single 'full' reaction as explained in Fig. 2. This was done to reduce the number of variables and equations considered in the model, so as to guarantee its robustness and speed the rate of system convergence. 

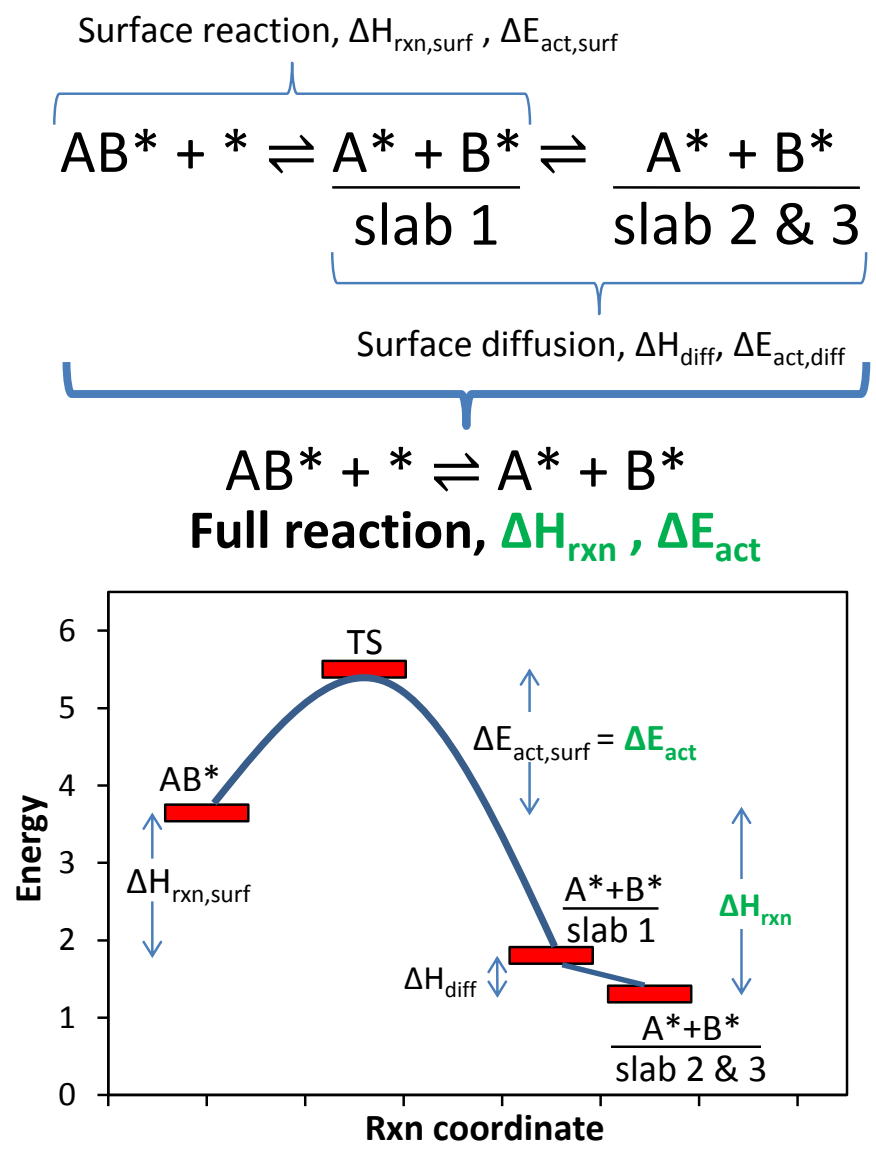

Fig. 2 Definition of reaction and activation energy based on surface reaction and surface diffusion. ' $\mathrm{A}^{*}+\mathrm{B}^{*} / \mathrm{slab} 1^{\prime}$ means that $\mathrm{A}$ and $\mathrm{B}$ are placed on the same slab (close to each other but as separate species), the slab is allowed to relax. ' $\mathrm{A}^{*}+\mathrm{B}^{*} / \mathrm{slab} 2 \& 3^{\prime}$ ' means that $\mathrm{A}$ and $\mathrm{B}$ are placed far from each other, or, in other words, placed in separate slabs and full relaxation is allowed. Further explanation to this approach can be found in [4].

Due to similar values for forward and reverse activation energies for some reactions, both forward and reverse reactions are considered in the model. The surface reaction rate constants for forward $\left(\mathrm{k}_{\mathrm{f}}\right)$ and reverse $\left(\mathrm{k}_{\mathrm{r}}\right)$ reactions are calculated as,

$$
\begin{aligned}
& \mathrm{k}_{\mathrm{f}}=\mathrm{A} \exp \left[\frac{-\mathrm{E}_{\mathrm{a}, \mathrm{f}}}{\mathrm{k}_{\mathrm{B}} \mathrm{T}}\right] \\
& \mathrm{k}_{\mathrm{r}}=\mathrm{A} \exp \left[\frac{-\mathrm{E}_{\mathrm{a}, \mathrm{r}}}{\mathrm{k}_{\mathrm{B}} \mathrm{T}}\right]
\end{aligned}
$$

where $E_{a, f}$ and $E_{a, r}$ are the activation energies of the forward and reverse reactions, respectively, $A$ is the pre-exponential factor, which is estimated as $k_{B} T / h, k_{B}$ is the Boltzmann constant, $T$ is 
absolute temperature, and $h$ is Planck's constant. The reaction rate constants for desorption processes are calculated using the Arrhenius expression as in eq. (6).

In the $\mathrm{LRhZ}$ pyrochlore MKM, the desorption barriers used for $\mathrm{CH}_{4}, \mathrm{CO}_{2}, \mathrm{H}_{2} \mathrm{O}, \mathrm{CH}_{3} \mathrm{OH}, \mathrm{CO}$ and $\mathrm{H}_{2}$ were assumed to be equivalent to the energy needed to desorb from the weakest adsorption site (see Table 1) because the adsorbates readily diffuse on the catalyst surface at the high temperatures at which DRM is carried out $(\sim 1000 \mathrm{~K})$. For similar reasons, each species in the model is considered to be adsorbed to the site with strongest adsorption energy. $\mathrm{CH}_{4}$ and $\mathrm{H}_{2}$ are considered in the model as species that occupy Rh sites; although strictly speaking, they do not have a formal bond with any surface metal atom due to the lack of dipole on the molecules. A list of the strongest adsorption sites and the corresponding adsorption energies for the species considered in the model can be found in the Supporting Information of [4]. Table 1 summarizes the species considered in the model and the identified most favorable active sites. The present model distinguishes between two types of sites: the Rh-sites and the non-Rh-sites. The Rh-sites refer to active sites where at least one $\mathrm{Rh}$-atom is involved; whereas, the non-Rh-sites refer to active sites where no Rh-atoms are involved.

Table 1 List of species considered in the LRhZ pyrochlore microkinetic model.

\begin{tabular}{|c|c|c|c|}
\hline \multicolumn{4}{|c|}{ Adsorbed species } \\
\hline \multicolumn{2}{|c|}{ On Rh-sites } & \multicolumn{2}{|c|}{ On non-Rh-sites } \\
\hline 1 & $\mathrm{CH}_{4} * \mathrm{Rh}$ & 12 & $\mathrm{H}_{2} \mathrm{O} *$ \\
\hline 2 & $\mathrm{H}_{2} * \mathrm{Rh}$ & 13 & $\mathrm{CH}_{3} \mathrm{OH}^{*}$ \\
\hline 3 & $\mathrm{CO} * \mathrm{Rh}$ & 14 & $\mathrm{CO}_{2} *$ \\
\hline 4 & $\mathrm{CH}_{2} \mathrm{O} * \mathrm{Rh}$ & 15 & $\mathrm{CHOH}^{*}$ \\
\hline 5 & $\mathrm{H}^{* \mathrm{Rh}}$ & 16 & $\mathrm{CH}_{3} *$ \\
\hline 6 & $\mathrm{COOH}^{* \mathrm{Rh}}$ & 17 & $\mathrm{CH}_{2} \mathrm{OH}^{*}$ \\
\hline 7 & $\mathrm{CHO}^{* \mathrm{Rh}}$ & 18 & $\mathrm{CH}_{3} \mathrm{O} *$ \\
\hline 8 & $\mathrm{CH}_{2} * \mathrm{Rh}$ & 19 & $\mathrm{OH}^{*}$ \\
\hline 9 & $\mathrm{CH}^{* \mathrm{Rh}}$ & & \\
\hline 10 & $\mathrm{O} * \mathrm{Rh}$ & & \\
\hline 11 & $\mathrm{C} * \mathrm{Rh}$ & & \\
\hline \multicolumn{4}{|c|}{ Gas phase species } \\
\hline \multicolumn{4}{|c|}{ Lowest desorption barrier $(\mathrm{eV})$} \\
\hline 20 & $\mathrm{CH}_{4(\mathrm{~g})}$ & & 0.03 \\
\hline 21 & $\mathrm{CO}_{2(\mathrm{~g})}$ & & 1.02 \\
\hline 22 & $\mathrm{H}_{2} \mathrm{O}_{(\mathrm{g})}$ & & 0.50 \\
\hline 23 & $\mathrm{H}_{2(\mathrm{~g})}$ & & 0.02 \\
\hline 24 & $\mathrm{CO}_{(\mathrm{g})}$ & & 1.62 \\
\hline 25 & $\mathrm{CH}_{3} \mathrm{OH}_{(\mathrm{g})}$ & & 0.52 \\
\hline
\end{tabular}




\section{Explicit forms of the rate equations for each intermediate}

The ODEs corresponding to the net change of surface coverage with respect to time have the general form:

$r_{i}=\frac{d \theta_{i}}{d t}=r_{\text {(formation of } \mathrm{i})}-r_{\text {(consumption of } \mathrm{i})}=0$

50 surface reactions are considered (counting forward and reverse reactions). A full list of reaction formulas, reaction energies and activation energies can be found in the Supporting Information (Table S3).

The rate of consumption/formation for reactants/products in the gas phase can be calculated as follows,

Water: $\quad \mathrm{r}_{\mathrm{H}_{2} \mathrm{O}_{(\mathrm{g})}}=\frac{\mathrm{d} \theta_{\mathrm{H}_{2} \mathrm{O}_{(\mathrm{g})}}}{\mathrm{dt}}=-\mathrm{k}_{30 \mathrm{r}}\left(\mathrm{P}_{\mathrm{H}_{2} \mathrm{O}(\mathrm{g})} \theta^{*}-\mathrm{K}_{30, \mathrm{eq}} \theta_{\mathrm{H}_{2} \mathrm{O}}\right)$

Methanol: $\quad \mathrm{r}_{\mathrm{CH}_{3} \mathrm{OH}_{(\mathrm{g})}}=\frac{\mathrm{d} \theta_{\mathrm{CH}_{3} \mathrm{OH}_{(\mathrm{g})}}}{\mathrm{dt}}=-\mathrm{k}_{34 \mathrm{r}}\left(\mathrm{P}_{\mathrm{CH}_{3} \mathrm{OH}(\mathrm{g})} \theta^{*}-\mathrm{K}_{34, \mathrm{eq}} \theta_{\mathrm{CH}_{3} \mathrm{OH}}\right)$

Carbon monoxide: $\quad \mathrm{r}_{\mathrm{CO}_{(\mathrm{g})}}=\frac{\mathrm{d} \theta_{\mathrm{CO}_{(\mathrm{g})}}}{\mathrm{dt}}=-\mathrm{k}_{33 \mathrm{r}}\left(\mathrm{P}_{\mathrm{CO}(\mathrm{g})} \theta^{* \mathrm{Rh}}-\mathrm{K}_{33, \mathrm{eq}} \theta_{\mathrm{CO}}\right)$

Hydrogen: $\quad \mathrm{r}_{\mathrm{H}_{2(\mathrm{~g})}}=\frac{\mathrm{d} \theta_{\mathrm{H}_{2(\mathrm{~g})}}}{\mathrm{dt}}=-\mathrm{k}_{32 \mathrm{r}}\left(\mathrm{P}_{\mathrm{H}_{2}(\mathrm{~g})} \theta^{* \mathrm{Rh}}-\mathrm{K}_{32, \mathrm{eq}} \theta_{\mathrm{H}_{2}}\right)$

Methane: $\quad \mathrm{r}_{\mathrm{CH}_{4(\mathrm{~g})}}=\frac{\mathrm{d} \theta_{\mathrm{CH}_{4(\mathrm{~g})}}}{\mathrm{dt}}=-\mathrm{k}_{\mathrm{lf}}\left(\mathrm{P}_{\mathrm{CH}_{4}(\mathrm{~g})} \theta^{* \mathrm{Rh}}-\frac{\theta_{\mathrm{CH}_{4}}}{\mathrm{~K}_{1, \mathrm{eq}}}\right)$

Carbon dioxide: $\quad \mathrm{r}_{\mathrm{CO}_{2(\mathrm{~g})}}=\frac{\mathrm{d} \theta_{\mathrm{CO}_{2(\mathrm{~g})}}}{\mathrm{dt}}=-\mathrm{k}_{6 \mathrm{f}}\left(\mathrm{P}_{\mathrm{CO}_{2}(\mathrm{~g})} \theta^{*}-\frac{\theta_{\mathrm{CO}_{2}}}{\mathrm{~K}_{6, \mathrm{eq}}}\right)$

\section{Reactor design equations}

Due to the complexity of the reaction system being modeled, a simple batch reactor model was assumed for these calculations. Though the batch reactor does not fully capture the dynamic behavior of a scaled-up plug flow reactor (PFR) system, the time evolution of reaction intermediates on the catalyst surface is similar for the two cases. Throughout the simulated operation of the reactor the moles and therefore the partial pressure of gaseous species vary, and 
this phenomenon is addressed through the balance of gas phase species inside the reactor using the batch reactor design equation.

The design equation for any batch reactor containing heterogeneous catalysts is:

$\frac{\mathrm{dC}_{\mathrm{A}(\mathrm{g})}}{\mathrm{dt}}=\mathbf{r}_{\mathrm{A}(\mathrm{g})}$

where $C_{A}$ is the concentration of gas phase species $A$ relative to the weight of heterogeneous catalyst present in the reactor (mol A/g-cat), $t$ is time, and $\mathbf{r}_{\mathbf{A}(\mathbf{g})}$ is the molar rate of production of species $A$ (mol A/g-cat).

In eq. (15), $\mathbf{r}_{\mathrm{A}(\mathrm{g})}$ has units of concentration (mol A/g-cat) per time; however, $\mathrm{r}_{\mathrm{A}(\mathrm{g})}$ is calculated from the solution of the set of differential equations corresponding to the rate expressions for the surface intermediates (eq. (9)-(14)) that have units of coverage (molecules/active site) per time. Thus,

$$
\frac{\mathrm{dC}_{\mathrm{A}(\mathrm{g})}}{\mathrm{dt}}=\mathrm{r}_{\mathrm{A}(\mathrm{g})}\left(\frac{\mathrm{s}}{\mathrm{N}_{\mathrm{a}} \omega}\right)
$$

where $s$ is the catalyst surface area per weight of catalyst $\left(8.72 \mathrm{~m}^{2} / \mathrm{g}\right.$ as measured by BET analysis) [5], $\omega$ is the approximate surface area per active site on the (111) plane $\left(1.28 \times 10^{-19} \mathrm{~m}^{2} /\right.$ active site $)$ and $N_{A}$ is the Avogadro's number. $C_{A(\mathrm{~g})}$ can be expressed as $n_{A(g)} / m_{c a t}$, where $n_{A(g)}$ is the moles of gas phase species $A$ and $m_{c a t}$ is the mass of catalyst in the reactor $(9 \mathrm{mg}$, matching data from experiments) [5]. Given that all of the catalyst is contained within the simulated batch reactor, one can then express eq. (16) as:

$$
\frac{\mathrm{dn}_{\mathrm{A}(\mathrm{g})}}{\mathrm{dt}}=\mathrm{r}_{\mathrm{A}(\mathrm{g})}\left(\frac{\mathrm{m}_{\mathrm{cat}} \mathrm{s}}{\mathrm{N}_{\mathrm{a}} \omega}\right)
$$

A set of 19 ODEs of the form of eq. (8) and a set of 6 ODEs of the form of eq. (17) are solved simultaneously to obtain the time evolution of both surface and gas phase species in the reactor for a specified set of conditions. A full list of the equations used in the model can be found in Supporting Information (section 'Rate equations considered in the micro-kinetic model').

\section{Model assumptions}

The doping percentage ( $w t \% R h$ ) of a Rh-substituted pyrochlore can be related to its molecular formula $\left(\mathrm{La}_{2} \mathrm{Zr}_{2-\mathrm{x}} \mathrm{Rh}_{\mathrm{x}} \mathrm{O}_{7}\right)$ as follows:

$$
\mathrm{x}=\frac{(\mathrm{wt} \% \mathrm{Rh})\left(2 \mathrm{M}_{\mathrm{La}}+2 \mathrm{M}_{\mathrm{Zr}}+7 \mathrm{M}_{\mathrm{O}}\right)}{\left(100 \mathrm{M}_{\mathrm{Rh}}-(\mathrm{wt} \% \mathrm{Rh})\left(\mathrm{M}_{\mathrm{Rh}}-\mathrm{M}_{\mathrm{Zr}}\right)\right)}
$$


where $x$ is the subscript in the formula $\mathrm{La}_{2} \mathrm{Zr}_{2-\mathrm{x}} \mathrm{Rh}_{\mathrm{x}} \mathrm{O}_{7}$, and $M_{R h}, M_{Z r}, M_{L a}$ and $M_{O}$ are the atomic masses for Rh, Zr, La and O, respectively. Derivation of eq. (18) can be found in Supporting Information (section 'Model assumptions').

Assuming each metal atom is an active site and there is perfect dispersion of metal atoms between the bulk and the surface of the catalyst, the fraction of Rh-sites $\left(\theta^{\mathrm{Rh}}\right)$ on the surface of the pyrochlore is calculated as follows,

Fraction of Rh-sites $\equiv \theta^{\mathrm{Rh}}=\frac{\mathrm{x}}{2+(2-\mathrm{x})+\mathrm{x}}$

and for the non-Rh-sites,

Fraction of non-Rh-sites $\equiv \theta^{\text {non-Rh }}=1-\theta^{\mathrm{Rh}}$

Therefore, for a $2 \mathrm{wt} \%$ substituted lanthanum zirconate pyrochlore catalyst $\left(\mathrm{La}_{2} \mathrm{Zr}_{1.888} \mathrm{Rh}_{0.112} \mathrm{O}_{7}\right)$ : $\mathrm{x}=0.112$ and $\theta^{\mathrm{Rh}}=0.028$.

Based on Table 1, the coverage of vacant Rh-sites can be calculated as:

$\theta^{* \mathrm{Rh}}=\theta^{\mathrm{Rh}}-\left(\theta_{\mathrm{CH}_{4}}+\theta_{\mathrm{H}_{2}}+\theta_{\mathrm{CO}}+\theta_{\mathrm{CH}_{2} \mathrm{O}}+\theta_{\mathrm{H}}+\theta_{\mathrm{COOH}}+\theta_{\mathrm{CHO}}+\theta_{\mathrm{CH}_{2}}+\theta_{\mathrm{CH}}+\theta_{\mathrm{O}}+\theta_{\mathrm{C}}\right)$

and the coverage of vacant non-Rh-sites as,

$\theta^{* \text { non- } \mathrm{Rh}}=\theta^{\mathrm{non}-\mathrm{Rh}}-\left(\theta_{\mathrm{H}_{2} \mathrm{O}}+\theta_{\mathrm{CH}_{3} \mathrm{OH}}+\theta_{\mathrm{CO}_{2}}+\theta_{\mathrm{CHOH}}+\theta_{\mathrm{CH}_{3}}+\theta_{\mathrm{CH}_{2} \mathrm{OH}}+\theta_{\mathrm{CH}_{3} \mathrm{O}}+\theta_{\mathrm{OH}}\right)$

The present MKM assumes that a species adsorbs only on the most stable site, even though its adsorption on multiple site types may be thermodynamically feasible. At sufficiently high pressures, if a species has a high adsorption energy on Rh and non-Rh sites sites, it could bind to both and reduce the number of available catalyst sites. As shown later in this paper (Fig. 8) and in Supporting Information (Fig. S5), none of the adsorbate forms for reactants $\left(\mathrm{CH}_{4} * \mathrm{Rh}, \mathrm{CO}_{2} *\right)$ has significant coverage of the surface; therefore, the assumption of selective adsorption proves to be valid.

Furthermore, it is assumed that the diffusion of species from the 'second' strongest adsorption site readily occurs at the high temperatures studied $\left(>450^{\circ} \mathrm{C}\right)$ as a result of relatively low energy barriers for diffusion; therefore, if the coverage of an adsorbed reactants is low (as shown in the coverage profiles, Fig. 8 and Fig. S5), it will most probably bind to the site yielding the strongest adsorption.

Transition from plug-flow reactor used in experiments to the modeled batch reactor 
The herein described batch reactor model with a perfectly mixed gas phase provides the opportunity to consider a broad set of surface intermediates and reactions and still achieve a robust model without having to account for the fluid mixing and diffusion phenomena that are essential to the performance of flow reactor systems.

Despite the species in the modeled batch reactor existing as a homogeneous mixture (different from what occurs in a plug flow reactor), the concentration profile of gas phase reactants and products with respect to the independent variable for the modeled batch system (time) correlates to the variation with axial distance in a PFR, as seen in Fig. S2 (Supporting Information). This analogy is used to show that DFT derived data can describe the experimental trends in $\mathrm{H}_{2}$-to-CO ratio and conversion, but the goal is not to fully reproduce the experimental data.

The initial moles of reactants inside the modeled batch reactor were calculated as follows,

$\mathrm{n}_{\mathrm{CH}_{4}, 0}=\mathrm{n}_{\mathrm{CO}_{2}, 0}=\mathrm{v}_{\mathrm{PFR}} \tau \mathrm{P}_{\text {line }} / \mathrm{RT}_{\text {room }}$

where $n_{\mathrm{CH}_{4}, \mathrm{O}}$ and $n_{\mathrm{CO}_{2}, \mathrm{O}}$ are the initial moles of $\mathrm{CH}_{4}$ or $\mathrm{CO}_{2}$ in the reactor, respectively. $n_{\mathrm{CH}_{4}, \mathrm{O}}$

equals $n_{\mathrm{CO}_{2}, 0}$ because the reactive system used was fed with an equimolar mixture of $\mathrm{CH}_{4}$ and $\mathrm{CO}_{2}$. $v_{P F R}$ is the volumetric flow of $\mathrm{CH}_{4}\left(\right.$ or $\left.\mathrm{CO}_{2}\right)$ fed to the PFR in the experiments, $\tau$ is the surface residence time at the reaction temperature found through Steady-State Isotopic Transient Kinetic Analysis (SSITKA) [5], $P_{\text {line }}$ is the pressure in the line feeding the reactant, $R$ is the gas constant and $T_{\text {room }}$ is the room temperature since the flowmeters were placed far from the furnace surrounding the reactor. For a more detailed description of the reactive system set-up refer to [5]. The volume of the modeled batch reactor $\left(\mathrm{V}_{\text {batch }}\right)$ was calculated as follows,

$\mathrm{V}_{\text {batch }}=\left(\mathrm{n}_{\mathrm{CH}_{4}, 0}+\mathrm{n}_{\mathrm{CO}_{2}, 0}+\mathrm{n}_{\text {Inert }, 0}\right) \cdot \mathrm{RT}_{\text {reactor }} / \mathrm{P}_{\text {reactor }}$,

and

$\mathrm{n}_{\text {Inert }, 0}=v_{\text {PFR,Inert }} \tau \mathrm{P}_{\text {line }} / \mathrm{RT}_{\text {room }}$

where $n_{\text {Inert }, 0}$ is the moles of the inert carrier gas, $T_{\text {reactor }}$ is the temperature inside the reactor and $P_{\text {reactor }}$ is the pressure inside the reactor. $P_{\text {line }}$ equals $P_{\text {reactor }}$ for the reactive system since the backpressure regulator in the experimental set-up was placed after the reactor.

\section{Results and Discussion}

\subsection{Validation of the model}

The LRhZ pyrochlore MKM was able to reproduce experimental trends remarkably well. In the reaction network, methanol and water were included as possible byproducts, despite methanol never being observed experimentally and water only being observed in small amounts. Analysis of predicted outcomes shows that the MKM model also does not favor the generation of these 
two byproducts, which corroborates the validity of the employed DFT data. As seen in Fig. 3, the trends in $\mathrm{CO}_{2}$ and $\mathrm{CH}_{4}$ conversion are properly described by the $\mathrm{LRhZ}$ pyrochlore MKM; furthermore, $\mathrm{CO}_{2}$ conversion is higher than $\mathrm{CH}_{4}$ conversion at each temperature, which suggests that the model correctly describes the propensity of the catalyst to activate the reverse water gasshift reaction (RWGS), which has been shown to be a competing reaction at low temperatures [5, $6]$.

The product concentrations predicted by the MKM model generally agreed with the experimental data after steady state had been achieved within the reactor. To ensure that steady state was achieved, species concentrations in the batch reactor were modeled for at least $1 \times 10^{7} \mathrm{~s}$; therefore, all data from the MKM reported in this work are at a reaction time of $1 \times 10^{7} \mathrm{~s}$. At many of the system conditions studied, steady state was reached at reaction times approaching 1,000 s (see later discussion), which is significantly longer than is required experimentally (normally less than $50 \mathrm{~s}$ ). This relatively longer time to achieve steady state is due to the fact that in the closed batch reactor with a clean catalyst (as modeled), the reactants must first populate the surface, increasing the required residence time. Additionally, residence times to achieve steady state are longer than experimentally observed because the activation energies used in the MKM are higher than values predicted from earlier experimental data by the approach used in our earlier DFT simulation work [2], where the atoms of the catalyst were fixed during Climbing-Image Nudge Elastic Band (CI-NEB) computations to calculate the activation energies. Therefore, energetics associated with transition states are systematically higher. Finally and most importantly, the total pressure and partial pressure of product species (see Supporting Information Figs. S1 and S3) are higher in the batch reactor as compared to the experimental plug flow system, which helps to enhance the rate of the reverse reaction thereby slowing the overall rate of production of DRM products.
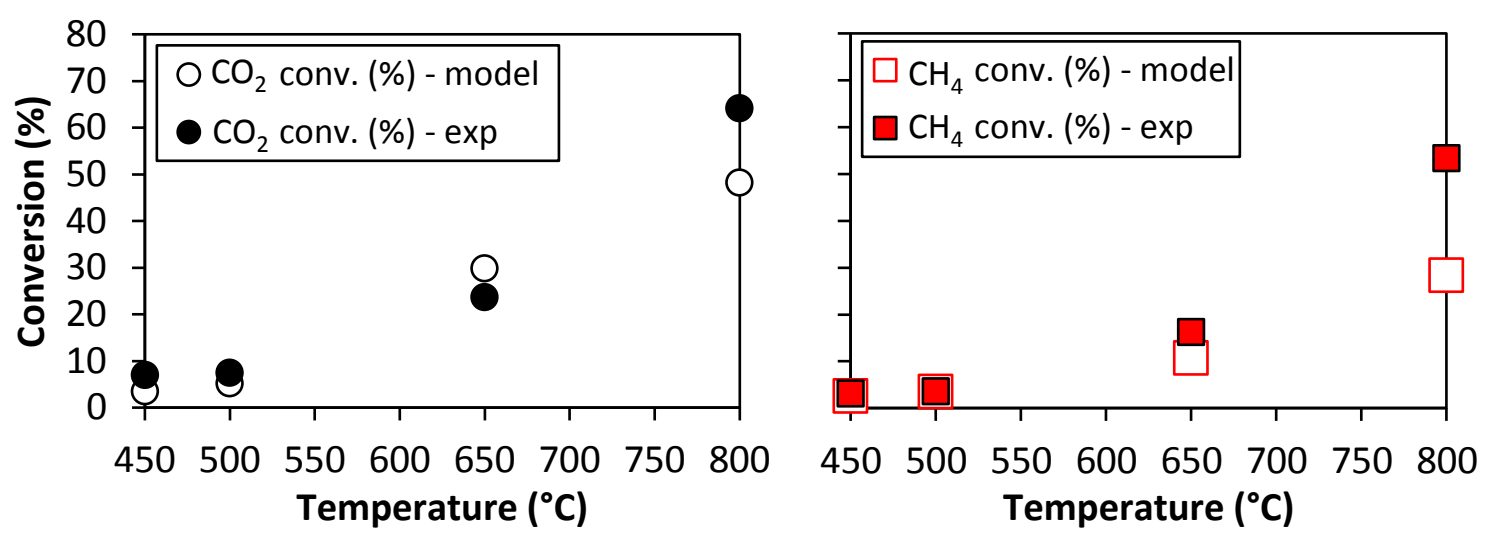

Fig. 3 Conversion of reactants for DRM over $2 \mathrm{wt} \% \mathrm{LRhZ}$ at $1.1 \mathrm{~atm}$. Comparison between MKM results and experimental data [5] at different temperatures $\left(450,500,650\right.$ and $\left.800{ }^{\circ} \mathrm{C}\right)$, with equimolar feed $\left(\mathrm{CO}_{2}\right.$ and $\left.\mathrm{CH}_{4}\right)$ and $\mathrm{GHSV}=65,333 \mathrm{~cm}^{3} / \mathrm{g}_{\mathrm{cat}} / \mathrm{h}$.

The $\mathrm{H}_{2}$ to $\mathrm{CO}$ molar ratio is a key parameter to evaluate reaction performance, as the closer this ratio is to unity, the higher energetic power has the syngas mixture. This product ratio was well 
described by the microkinetic model (see Fig. 4), and the decrease in this ratio at lower temperatures is consistent with the coexistence of the RWGS reaction that the model addresses.

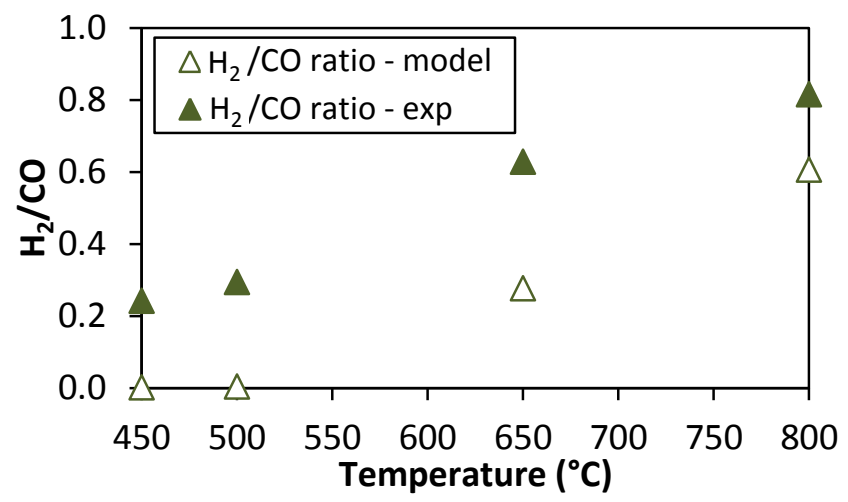

Fig. $4 \mathrm{H}_{2}$ to $\mathrm{CO}$ molar ratio for DRM over $2 \mathrm{wt} \% \mathrm{LRhZ}$ at $1.1 \mathrm{~atm}$. Comparison between MKM results and experimental data [5] at different temperatures $\left(450,500,650\right.$ and $\left.800{ }^{\circ} \mathrm{C}\right)$, with equimolar feed $\left(\mathrm{CO}_{2}\right.$ and $\left.\mathrm{CH}_{4}\right)$ and $\mathrm{GHSV}=65,333 \mathrm{~cm}^{3} / \mathrm{g}_{\mathrm{cat}} / \mathrm{h}$.

In a plug-flow reactor, the pressure in the reactor is maintained at a relatively constant value; however, in the modeled batch reactor the overall pressure and more specifically the partial pressure of product species are relatively higher at the final steady state conversion conditions. This increase in overall pressure and product partial pressures results from the DRM reaction causing an increase in the number of moles with reaction (i.e., $\mathrm{CH}_{4}+\mathrm{CO}_{2} \rightleftharpoons 2 \mathrm{CO}+2 \mathrm{H}_{2}$ ). As the DRM reaction is reversible, the increased partial pressure of product species leads to an overall decrease in the modeled conversion at a given reaction temperature and initial partial pressure of reactants.

\subsection{Pressure influence on reaction performance}

Predictions from our model show how an increase in the reactor pressure has little impact on the obtained $\mathrm{H}_{2}$ to $\mathrm{CO}$ ratio, but is detrimental to the overall conversion of reactants (see Fig. 5). Jafarbegloo et al. [29] reported in their thermodynamic equilibrium analysis of dry reforming of methane that equilibrium conversions for $\mathrm{CH}_{4}$ and $\mathrm{CO}_{2}$ decrease monotonically when increasing pressure from 1 to $9.9 \mathrm{~atm}$, at $800{ }^{\circ} \mathrm{C}$ using a stoichiometric feed, which is the same trend obtained from the MKM as shown in Fig. 5. However, their studies indicated that the $\mathrm{H}_{2}$ to $\mathrm{CO}$ ratio decreases from 0.94 to 0.77 with increasing pressure (from 1 to $9.9 \mathrm{~atm}$ ) at $800{ }^{\circ} \mathrm{C}$ and equimolar feed, suggesting an increase in the extent of RWGS occurring, whereas the MKM data presented here show a somewhat increasing $\mathrm{H}_{2}$ to $\mathrm{CO}$ ratio over a similar range of pressures, see Fig. 5. 


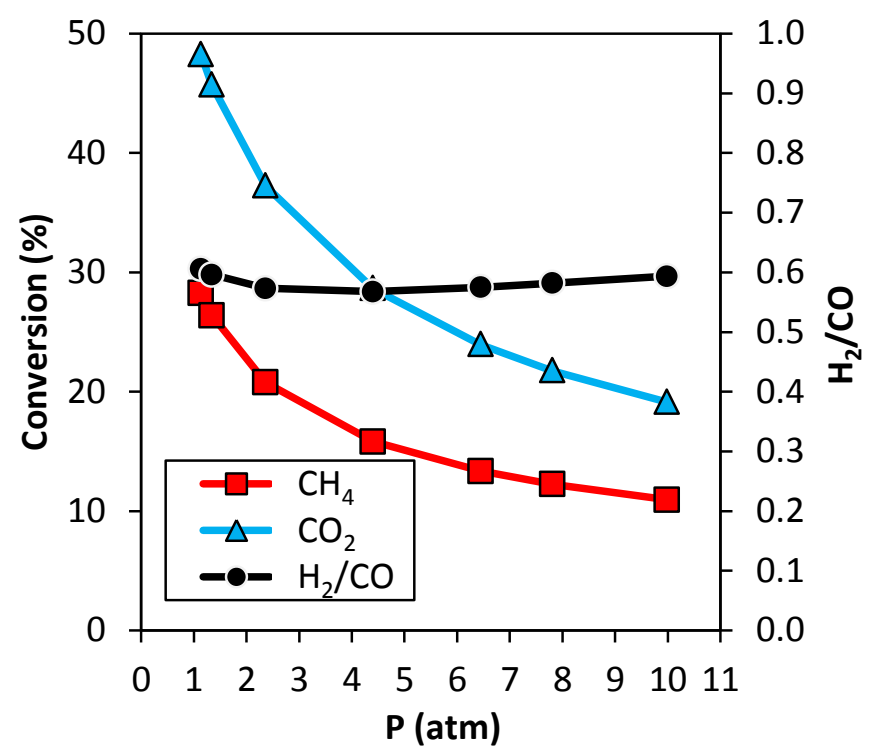

Fig. 5 Calculated (from MKM) pressure influence on conversion of reactants and $\mathrm{H}_{2}$ to $\mathrm{CO}$ ratio for DRM over $2 \mathrm{wt} \% \mathrm{LRhZ}$ at $800{ }^{\circ} \mathrm{C}$.

$\mathrm{DRM}$ is a reaction where there is a positive change in the total number of moles with reaction $\left(\mathrm{CH}_{4}+\mathrm{CO}_{2} \rightleftharpoons 2 \mathrm{CO}+2 \mathrm{H}_{2}\right)$, whereas the competing reaction, RWGS $\left(\mathrm{H}_{2}+\mathrm{CO}_{2} \rightleftharpoons \mathrm{CO}+\mathrm{H}_{2} \mathrm{O}\right)$, is net neutral in terms of a change in the number of total moles with reaction. At relatively high pressures and temperatures, it is more favorable for the $\mathrm{H}_{2}$ generated through DRM to undergo the reverse DRM reaction yielding $\mathrm{CH}_{4}$ and $\mathrm{CO}_{2}$ as compared to hydrogen being consumed by the RWGS reaction, due to there being a decrease in the total number of moles with DRM. This leads to a reduction in RWGS rates and is why the present MKM predicts a slight increase in the $\mathrm{H}_{2}$ to $\mathrm{CO}$ ratio with increasing pressure, as shown in Fig. 5. The predicted increase in the $\mathrm{H}_{2} / \mathrm{CO}$ ratio is slight because the total change in system pressure is also relatively small. Calculations by Jafarbegloo et al. [29] use a thermodynamic analysis of DRM and RWGS that explicitly accounts for equilibrium system pressure effects, but their model does not include pressure effects on the reaction kinetics, specifically related to adsorption and desorption rates.

\subsection{Rh-doping percentage influence on reaction performance}

At high temperatures $\left(800{ }^{\circ} \mathrm{C}\right)$, the doping percentage of $\mathrm{Rh}$ in the pyrochlore catalyst has only a minor influence on the reaction performance, as high temperatures favor surface diffusion of intermediates and thus available $\mathrm{Rh}$ atoms on the surface are easily accessed. At moderate temperatures $\left(650{ }^{\circ} \mathrm{C}\right)$, however, the quantity of $\mathrm{Rh}$ atoms at the catalyst surface has a greater impact on catalyst performance due to the decreased mobility of surface intermediates, see Fig. 6. Thus, at surface Rh loadings below a specific value the reaction performance drops precipitously. From our calculations, the DRM performance at $650^{\circ} \mathrm{C}$ and $1.1 \mathrm{~atm}$ drops significantly with Rh doping levels less than approximately $0.4 \mathrm{wt} \%$; nevertheless, further 
experimental data are required to verify the accuracy of the model as it relates to predictions of the minimum required $\mathrm{Rh}$ doping percentage.
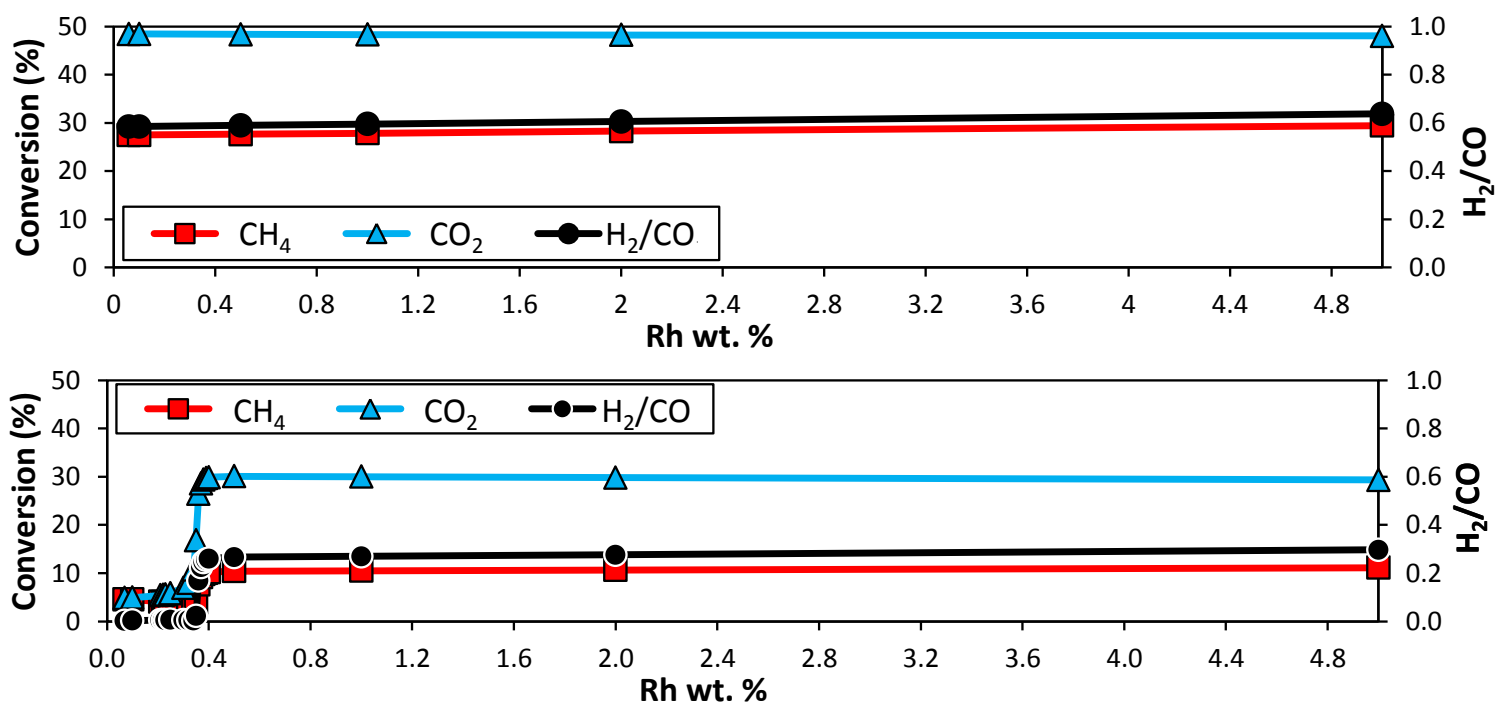

Fig. 6 Calculated (using MKM) influence of Rh-doping percentage on the conversion of $\mathrm{CO}_{2}$ and $\mathrm{CH}_{4}$ reactants and $\mathrm{H}_{2}$ to $\mathrm{CO}$ ratio for DRM over LRhZ pyrochlore catalysts at $1.1 \mathrm{~atm}$ and $800{ }^{\circ} \mathrm{C}$ (upper graph) and $650{ }^{\circ} \mathrm{C}$ (lower graph). 


\subsection{Reaction mechanism with respect to time}

The MKM presented in this work describes the reaction network presented in Fig. $7 \mathrm{a}$.



Fig. 7 a) Reaction network and b) Main reaction routes for DRM on the (111) plane of the LRhZ pyrochlore. The values above, below and next to the arrows are the reaction activation energies in $\mathrm{eV}$, and the small arrows next to these values indicate what direction each activation energy corresponds to. Reprinted from J. Catal., 333, Felipe Polo-Garzon, Ming He, David A. Bruce, Ab Initio Derived Reaction Mechanism for the Dry Reforming of Methane on Rh Doped Pyrochlore Catalysts, 59-70, Copyright (2016), with permission from Elsevier [4].

When the reaction mechanism is qualitatively described by effective activation energies for combined surface diffusion and reaction processes, the resulting main reaction pathway has two possible routes for $\mathrm{CH}_{4}$ dehydrogenation/oxygenation to form $\mathrm{CO}$ as shown in Fig. 7b. The branch that leads to $\mathrm{CH}$ formation has a slightly lower activation energy $\left(\Delta \mathrm{E}_{\mathrm{act}, \mathrm{f}}=2.53 \mathrm{eV}\right)$ than the branch that leads to $\mathrm{CH}_{2} \mathrm{O}$ formation $\left(\Delta \mathrm{E}_{\text {act, } \mathrm{f}}=2.88 \mathrm{eV}\right)$, nonetheless, once $\mathrm{CH}$ is formed, it encounters very high activation barriers to form $\mathrm{CO}_{(\mathrm{g})}$ (either $3.37 \mathrm{eV} \rightarrow 3.31 \mathrm{eV} \rightarrow 1.62 \mathrm{eV}$ through one route, or $4.01 \mathrm{eV} \rightarrow 2.40 \mathrm{eV} \rightarrow 1.62 \mathrm{eV}$ through an alternate route). On the other hand, if $\mathrm{CH}_{2} \mathrm{O}$ is formed the activation barriers encountered to form $\mathrm{CO}_{(\mathrm{g})}$ are considerably lower $(1.37 \mathrm{eV} \rightarrow 2.40 \mathrm{eV} \rightarrow 1.62 \mathrm{eV})$. Thus, $\mathrm{CH}_{4}$ dehydrogenation/oxygenation is proposed to mainly proceed as: $\mathrm{CH}_{4(\mathrm{~g})} \rightarrow \mathrm{CH}_{4} * \rightarrow \mathrm{CH}_{3} * \rightarrow \mathrm{CH}_{2} * \rightarrow \mathrm{CH}_{2} \mathrm{O}^{*} \rightarrow \mathrm{CHO}^{*} \rightarrow \mathrm{CO}^{*} \rightarrow \mathrm{CO}_{(\mathrm{g})}$. 
$\mathrm{CO}_{2}$ dissociation proceeds mainly through direct dissociation into adsorbed $\mathrm{CO}$ and atomic oxygen, with a dissociation barrier of $1.26 \mathrm{eV}$. Nonetheless, $\mathrm{H}$-induced $\mathrm{CO}_{2}$ decomposition may coexist since the barriers involved in this processes are also low. [4]

From this qualitative analysis of the $\mathrm{CH}_{4}$ dehydrogenation, one can conclude that $\mathrm{CH}$ is formed on the surface but acts rather as a spectator, especially on Rh containing sites, since further dehydrogenation and later oxygenation involves high activation barriers. Results from the $\mathrm{LRhZ}$ pyrochlore MKM support the existence of $\mathrm{CH}$ on the catalyst surface as a spectator as shown in Fig. 8. In fact, $\mathrm{CH}$ possesses the greatest surface coverage on $\mathrm{Rh}$-sites and remains adsorbed on the surface even after steady state is reached even though it does not belong to the main reaction pathway. Similarly, some atomic carbon is deposited on the catalyst surface, where it acts as a spectator. However, the observed rate of carbon deposition is significantly slower than the rate of DRM product formation, which helps explain why LRhZ pyrochlore catalysts shows very low carbon deposition when used for DRM [6].

In a previous work by Pakhare et al. [7], FTIR studies were performed over LRhZ pyrochlores to distinguish between the reactive oxycarbonate species from the spectator ones. In their experiment, a pretreated pyrochlore catalyst was initially dosed with $\mathrm{CO}_{2}$, then the catalyst was exposed to $10 \mathrm{CH}_{4} / \mathrm{He}$ pulses. After the $10^{\text {th }}$ pulse, $\mathrm{CO}_{2}$ was re-adsorbed to study the regrowth of any oxycarbonate species. When comparing the FTIR spectra after $\mathrm{CO}_{2}$ adsorption, after the $10^{\text {th }} \mathrm{CH}_{4}$ pulse and after readsorbing $\mathrm{CO}_{2}$, no $\mathrm{C}-\mathrm{H}$ stretching bands were observed at about 2800 $\mathrm{cm}^{-1}$ for the 2 and $5 \mathrm{wt} \% \mathrm{LRhZ}$ pyrochlores, suggesting the dissociative adsorption of $\mathrm{CH}_{4}$. In the present model, however, $\mathrm{CH}$ is suggested as a spectator. The difference between the present findings and the observation in the experiments by Pakhare et al. [7] can be explained through DFT-data reported in our previous work [4]. The preferred adsorption site for $\mathrm{CH}$ on the plane (111), which is the LRhZ pyrochlore surface most catalytically active for DRM, is a Rhcontaining site, more specifically, the 3-fold Rh-Zr-Zr site. Due to the low Rh substitution (2 and $5 \mathrm{wt} \%$ ) in the LRhZ pyrchlore used in the experiments by Pakhare et al. [7], the CH coverage on the overall catalyst surface is expected to be very low, so that the intensity of the IR mode for C$\mathrm{H}$ bond stretching is negligible when compared to bands associated with species adsorbed on non-Rh sites, such as adsorbed $\mathrm{CO}_{2}$ [4]. For instance, in our model, at $800{ }^{\circ} \mathrm{C}$ and $1.1 \mathrm{~atm}$, the surface coverage of $\mathrm{CH}$ on the $2 \mathrm{wt} \% \mathrm{LRhZ}$ pyrochlore is no greater than $2.6 \%$ (see Fig. 8). Additionally, the predicted surface coverage for select carbonate species observed in the FTIR studies by Pakhare et al. [7], where $\mathrm{CO}_{2}$ rich feed gas was present, are not appreciable in our MKM studies of DRM because the model included a stoichiometric feed containing $\mathrm{CH}_{4}$ and $\mathrm{CO}_{2}$, and the experimentally observed carbonate species that are involved in the DRM reaction are quickly consumed when methane is also present. Other spectator carbonate species observed by FTIR are not predicted by the present MKM model as a result of only lowest energy pathway reactions being included in the model.

In Fig. 8, a maximum in $\mathrm{CH}$ coverage corresponds to a minimum in $\mathrm{O}$ coverage, since high $\mathrm{CH}$ coverage indicates that the reaction is favored through the $\mathrm{CH}_{2} \mathrm{O}$ intermediate and thus more 
oxygen is consumed to oxygenate $\mathrm{CH}_{2}$. In addition, the disappearance of $\mathrm{CH}_{3}$ and $\mathrm{CH}_{2}$ towards the steady-state conditions inside the modeled reactor suggests that these two species belong to the low surface residence time $\mathrm{CH}_{4}$ dehydrogenation pathway shown in Fig. $7 \mathrm{~b}$.

The time evolution of surface and gas phase (see Supporting Information, Fig. S 1) species supports the main reaction pathway deduced from the activation energies of the elementary reaction steps and clearly shows the role played by intermediates along the DRM pathway. Results from the MKM model clearly show that the existence of specific surface intermediates does not necessarily mean that those intermediates belong to the main reaction pathway. Thus, the present work evidences the importance of advanced experimental surface techniques that look at the time evolution of intermediates on the surface, such as combined FTIR/SSITKA approaches.

To further elucidate the importance of specific reactions on the overall reaction rate, the MKM was run while considering only the suspected key reactions shown in Fig. 7b. The results from this simplified model showed that the time evolution of surface species were identical to the those shown in Fig. 8 for the more comprehensive reaction mechanism. Furthermore, the $\mathrm{H}_{2} / \mathrm{CO}$ ratio, $\mathrm{CH}_{4}$ conversion and $\mathrm{CO}_{2}$ conversion held the same to $0.61,28 \%$ and $48 \%$, respectively. This confirms that the set of relevant reactions for DRM over the LRhZ catalyst was discerned correctly.

Another variation of the MKM examined product distributions when the rate of reactions involving consumption or production of $\mathrm{CH}^{*}$ and $\mathrm{C}^{*}$ were set to zero. For this scenario, the time evolution of species on the non-Rh sites was almost unaltered; whereas, the Rh-sites were largely covered by oxygen atoms at steady state conditions (see Supporting Information, Fig. S4). Thus, the absence of $\mathrm{CH}^{*}$ and $\mathrm{C}^{*}$ on the surface extinguishes a driving force for the oxygenation reactions that lead to $\mathrm{CHO}$ and $\mathrm{CO}$; therefore, oxygen becomes more abundant according to the model. The $\mathrm{H}_{2} / \mathrm{CO}$ ratio reported by the model (0.57) drifted further apart from the experimental ratio (0.81) over the $2 \mathrm{wt} \% \mathrm{LRhZ}$ pyrochlore catalyst at $800{ }^{\circ} \mathrm{C}$ and $1.1 \mathrm{~atm}$, since ways for $\mathrm{CH}_{4}$ dehydrogenation (through $\mathrm{CH}^{*}$ and $\mathrm{C}^{*}$ ) were suppressed. The conversions of $\mathrm{CH}_{4}$ and $\mathrm{CO}_{2}$ remained roughly constant after substraction of $\mathrm{CH}^{*}$ and $\mathrm{C}^{*}$ from the model $(27 \%$ and $50 \%$, respectively). 

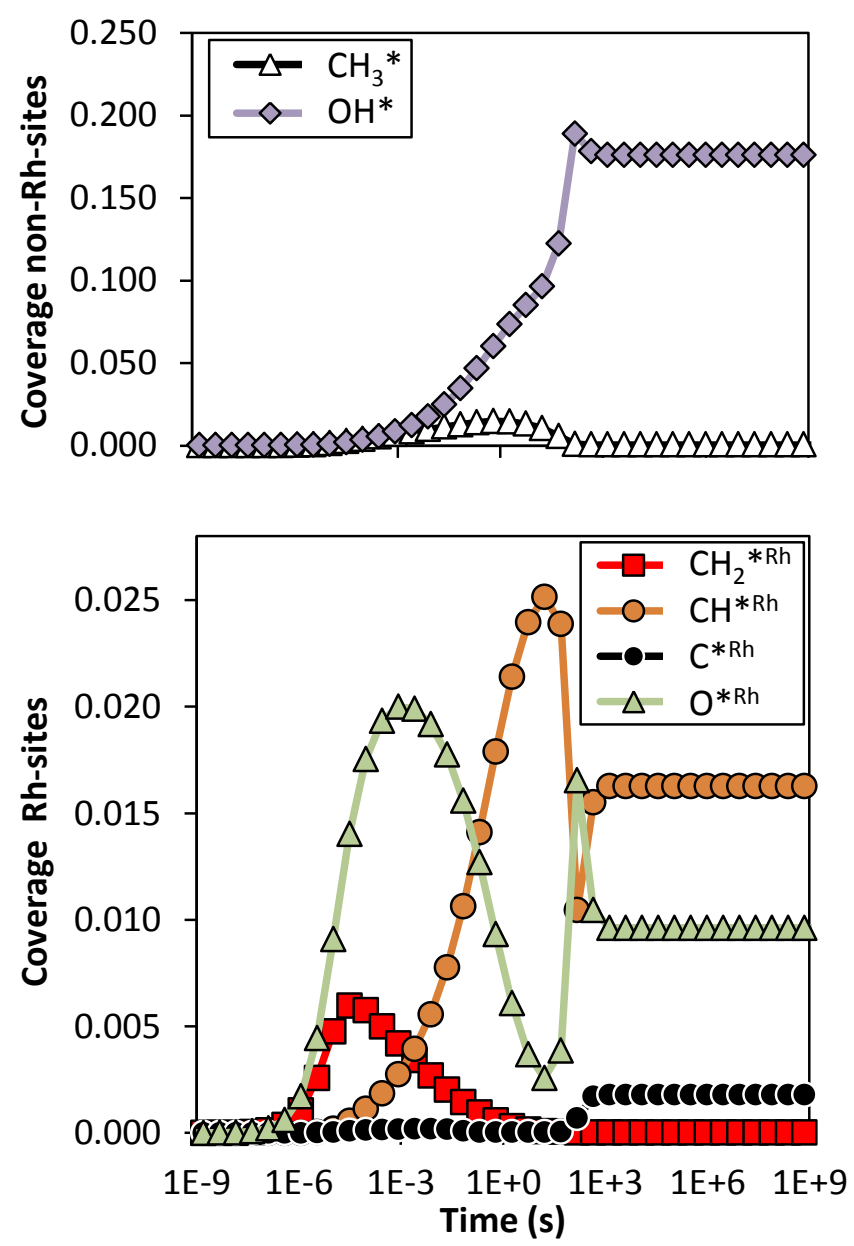

Fig. 8 Coverage of surface intermediates as a function of time for DRM over $2 \mathrm{wt} \% \mathrm{LRhZ}$ pyrochlore catalysts at $800{ }^{\circ} \mathrm{C}$ and $1.1 \mathrm{~atm}$.

$\mathrm{CH}_{4}$ and $\mathrm{CO}_{2}$ have relatively low activation energies for dissociation $(0.89$ and $1.26 \mathrm{eV}$, respectively) when compared to the highest activation energies in the main reaction path (Fig. 7b)), such as, $2.88 \mathrm{eV}$ for $\mathrm{CH}_{2}$ oxygenation to $\mathrm{CH}_{2} \mathrm{O}$ and $2.40 \mathrm{eV}$ for $\mathrm{CHO}$ dehydrogenation to $\mathrm{CO}$. Therefore, it is expected that the adsorption sites occupied by $\mathrm{CH}_{4}$ and $\mathrm{CO}_{2}$ are rapidly depleted of adsorbates, as seen in Fig. 8 at $800^{\circ} \mathrm{C}$ and also in Fig. S5 (Supporting information) at $450{ }^{\circ} \mathrm{C}$. This supports the assumption of selective adsorption on the Rh-sites and the non-Rh sites presented in the section 'Model assumptions' of this manuscript.

\section{Conclusions}

The presented DFT-based microkinetic model (MKM) accurately accounts for the collective behavior of a complex set of reactions (62 reactions), provides the time evolution of both gas phase species and surface intermediates and has multiple tunable reaction conditions. The model provides a generally accurate description of the trends in reactant $\left(\mathrm{CO}_{2}\right.$ and $\left.\mathrm{CH}_{4}\right)$ conversion 
with temperature, as well the change in $\mathrm{H}_{2}$ to $\mathrm{CO}$ ratio with temperature. This shows that the MKM can successfully account for the partial inhibition of the dry reforming reaction due to the coexistence of the competing reverse water gas shift reaction, which produces water.

Furthermore, the model did not suggest production of methanol, as observed experimentally [5], even though the reaction network, upon which the model equations were laid out, provided a theoretical route for methanol formation. This allowed cross-checking of the reliability of the model and validates the DFT data found in our earlier work [4] against experimental data [5].

Trends in reactant conversion with increases in pressure were well described by the model when compared to thermodynamic data [29], and the analysis of the influence of the Rh-doping percentage on the reaction performance suggests a critical value, which sets the ground for future experimental research on the optimal surface loading of the Rh dopant.

The main pathway for $\mathrm{CH}_{4}$ dehydrogenation/oxygenation is explained in a time scale by the MKM: $\mathrm{CH}_{4(\mathrm{~g})} \rightarrow \mathrm{CH}_{4} * \rightarrow \mathrm{CH}_{3} * \rightarrow \mathrm{CH}_{2} * \rightarrow \mathrm{CH}_{2} \mathrm{O}^{*} \rightarrow \mathrm{CHO}^{*} \rightarrow \mathrm{CO}^{*} \rightarrow \mathrm{CO}_{(\mathrm{g})}$; as well as the $\mathrm{CO}_{2}$ decomposition pathway: $\mathrm{CO}_{2(\mathrm{~g})} \rightarrow \mathrm{CO}_{2} * \rightarrow \mathrm{CO}^{*} \rightarrow \mathrm{CO}_{(\mathrm{g})}$ or $\mathrm{CO}_{2(\mathrm{~g})} \rightarrow \mathrm{CO}_{2} * \rightarrow \mathrm{COOH}^{*} \rightarrow$ $\mathrm{CO}^{*} \rightarrow \mathrm{CO}_{(\mathrm{g})}$. $\mathrm{CH}^{*}$ is identified as the primary reaction spectator, followed by atomic carbon, but in considerably less quantities, which explains the low rates of carbon deposition observed experimentally with this catalyst. This detailed understanding of species evolution on the surface is as yet inaccessible through experimental techniques and therefore emphasizes the significance of the present work in educating future pyrochlore catalyst optimization efforts.

\section{Acknowledgements}

This material is based upon work supported as part of the Center for Atomic Level Catalyst Design, an Energy Frontier Research Center funded by the U.S. Department of Energy, Office of Science, Office of Basic Energy Sciences under Award Number DE-SC0001058.

We thank Dr. Ming He, former graduate student in the Chemical and Biomolecular Engineering Department at Clemson University, for helpful discussions about the modeling techniques. We also thank Dr. James J. Spivey in the Chemical Engineering Department at Louisiana State University and Dr. Devendra Pakhare at Pyrochem Catalyst Company for helpful discussions about experimental observations related to catalyst performance.

We acknowledge the helpful staff and computational resources affiliated with the Clemson University high-performance computing facility, The Palmetto cluster. We also thank Dr. Rachel B. Getman in the Chemical and Biomolecular Engineering Department at Clemson University for helpful discussions about quantum simulation techniques. 


\section{References}

[1] W. Zhang, Fuel Process. Technol. 91 (2010) 866.

[2] L.S. Tan, K.K. Lau, M.A. Bustam, A.M. Shariff, J. Nat. Gas Chem. 21 (2012) 7.

[3] A.P.E. York, T. Xiao, M.L.H. Green, J.B. Claridge, Catal. Rev. 49 (2007) 511.

[4] F. Polo-Garzon, M. He, D.A. Bruce, J. Catal. 333 (2016) 59.

[5] F. Polo-Garzon, D. Pakhare, J.J. Spivey, D.A. Bruce, ACS Catal. (2015) in review.

[6] D. Pakhare, H. Wu, S. Narendra, V. Abdelsayed, D. Haynes, D. Shekhawat, D. Berry, J. Spivey, Appl. Petrochem. Res. 3 (2013) 117.

[7] D. Pakhare, V. Schwartz, V. Abdelsayed, D. Haynes, D. Shekhawat, J. Poston, J. Spivey, J. Catal. 316 (2014) 78.

[8] S. Dahl, A. Logadottir, C.J.H. Jacobsen, J.K. Nørskov, Appl. Catal. A: Gen. 222 (2001) 19.

[9] R.Y. Brogaard, R. Henry, Y. Schuurman, A.J. Medford, P.G. Moses, P. Beato, S. Svelle, J.K. Nørskov, U. Olsbye, J. Catal. 314 (2014) 159.

[10] G. Li, E.A. Pidko, I.A.W. Filot, R.A. van Santen, C. Li, E.J.M. Hensen, J. Catal. 308 (2013) 386.

[11] D. Teschner, R. Farra, L. Yao, R. Schlögl, H. Soerijanto, R. Schomäcker, T. Schmidt, L. Szentmiklósi, A.P. Amrute, C. Mondelli, J. Pérez-Ramírez, G. Novell-Leruth, N. López, J. Catal. 285 (2012) 273. 
[12] H.Y. Kim, S.S. Han, J.H. Ryu, H.M. Lee, J. Phys. Chem. C 114 (2010) 3156.

[13] S. Kandoi, A.A. Gokhale, L.C. Grabow, J.A. Dumesic, M. Mavrikakis, Catal. Lett. 93 (2004) 93.

[14] A.J. Medford, A.C. Lausche, F. Abild-Pedersen, B. Temel, N.C. Schjødt, J.K. Nørskov, F. Studt, Top. Catal. 57 (2014) 135.

[15] G. Prieto, S. Beijer, M.L. Smith, M. He, Y. Au, Z. Wang, D.A. Bruce, K.P. de Jong, J.J.

Spivey, P.E. de Jongh, Angew. Chem. Int. Ed. 53 (2014) 6397.

[16] A.J. Medford, J. Sehested, J. Rossmeisl, I. Chorkendorff, F. Studt, J.K. Nørskov, P.G.

Moses, J. Catal. 309 (2014) 397.

[17] Z. Wang, X.M. Cao, J. Zhu, P. Hu, J. Catal. 311 (2014) 469.

[18] G. Kresse, J. Hafner, Phys. Rev. B 47 (1993) 558.

[19] G. Kresse, J. Hafner, Phys. Rev. B 49 (1994) 14251.

[20] G. Kresse, J. Furthmüller, Comput. Mater. Sci. 6 (1996) 15.

[21] G. Kresse, J. Furthmüller, Phys. Rev. B 54 (1996) 11169.

[22] Y.D. Scherson, S.J. Aboud, J. Wilcox, B.J. Cantwell, J. Phys. Chem. C 115 (2011) 11036.

[23] P.E. Blöchl, Phys. Rev. B 50 (1994) 17953.

[24] G. Kresse, D. Joubert, Phys. Rev. B 59 (1999) 1758. 
[25] J.P. Perdew, K. Burke, M. Ernzerhof, Phys. Rev. Lett. 77 (1996) 3865.

[26] A.C. Hindmarsh, P.N. Brown, K.E. Grant, S.L. Lee, R. Serban, D.E. Shumaker, C.S.

Woodward, ACM Trans. Math. Softw. 31 (2005) 363.

[27] S.D. Cohen, A.C. Hindmarsh, Comput. Phys. 10 (1996) 138.

[28] R.D. Cortright, J.A. Dumesic, Adv. Catal. 46 (2001) 161.

[29] M. Jafarbegloo, A. Tarlani, A.W. Mesbah, S. Sahebdelfar, Int. J. Hydrog. Energy 40 (2015) 2445. 